Revista Eletrônica de Direito Processual - REDP. Volume 16. Julho a dezembro de 2015

Periódico Semestral da Pós-Graduação Stricto Sensu em Direito Processual da UERJ

Patrono: José Carlos Barbosa Moreira. ISSN 1982-7636. pp. 391-415 http://www.e-publicacoes.uerj.br/index.php/redp/index

\title{
ASPECTOS PROCEDIMENTAIS DA TUTELA DE URGÊNCIA SATISFATIVA REQUERIDA EM CARÁTER ANTEDECENTE ${ }^{1}$
}

\section{PROCEDURAL ASPECTS OF URGENT SATISFYING TUTELAGE REQUIRED ON} AN ANTECEDENT BASIS

Marco Félix Jobim

Doutor em Direito pela Pontifícia Universidade Católica do

Rio Grande do Sul. Professor dos Cursos de Graduação e Pós-Graduação em Direito na Pontifícia Universidade Católica do Rio Grande do Sul. Advogado marco@jobimesalzano.com.br

Fabricio Costa Pozatti

Mestrando em Direito pela Pontifícia Universidade Católica do Rio Grande do Sul. Especialista em Direito do Consumidor e Direitos Fundamentais pela Universidade Federal do Rio Grande do Sul. Advogado.

RESUMO: Trata-se de estudo que analisa a tutela de urgência de natureza satisfativa, com o objetivo de esclarecer como esta espécie de tutela é disciplinada no Código de Processo Civil de 2015, diferenciando-a das demais hipóteses de tutela provisória, identificando os requisitos necessários para a sua concessão e, principalmente, explorando os aspectos procedimentais da tutela de urgência satisfativa requerida em caráter antecedente.

PALAVRAS-CHAVE: Tutela de Urgência. Natureza Satisfativa. Requisitos. Procedimento. Antecedente.

\footnotetext{
${ }^{1}$ Artigo recebido em 20/09/2015 e aprovado em 27/11/2015.
} 
Revista Eletrônica de Direito Processual - REDP. Volume 16. Julho a dezembro de 2015

Periódico Semestral da Pós-Graduação Stricto Sensu em Direito Processual da UERJ

Patrono: José Carlos Barbosa Moreira. ISSN 1982-7636. pp. 391-415 http://www.e-publicacoes.uerj.br/index.php/redp/index

ABSTRACT: It is a study that analyzes the emergency tutelage of satisfying kind, in order to clarify how this kind of tutelage is regulated by the Civil Procedure Code of 2015, by differentiating it from other hypotheses of interim tutelage, identifying the requirements for its grant and, mostly exploring the procedural aspects of urgency satisfying tutelage required in antecedent character.

KEYWORDS: Urgent Tutelage. Satisfying Kind. Requirements. Procedure. Antecedent.

SUMÁRIO: 1. Considerações iniciais. 2. Tutela provisória. 3. Tutela de urgência satisfativa. 3.1. Momento do requerimento. 3.2. Requisitos necessários para a sua concessão. 3.2.1. Requerimento da parte interessada. 3.2.2. Probabilidade do direito. 3.2.3. Perigo de dano. 3.2.4. Irreversibilidade dos efeitos da decisão. 3.3. Motivação da decisão. 3.4. Medidas para a efetivação da medida. 4. A tutela de urgência satisfativa requerida em caráter antecedente. 4.1. Exigências relativas ao conteúdo do requerimento. 4.2. Prosseguimento da ação quando a tutela de urgência não for concedida. 4.3. Prosseguimento da ação quanto a tutela de urgência for concedida. 4.3.1. A interposição (ou não) de recurso. 4.3.2. Hipótese de não aditamento da petição inicial pelo autor e, ao mesmo tempo, de não interposição de recurso pelo réu. 4.3.3. A estabilização da tutela antecipada. 5. Considerações finais.

SUMMARY: 1. Initial considerations. 2. Interim tutelage. 3. Urgency satisfying tutelage. 3.1. Moment of the application. 3.2. Necessary requirements for granting. 3.2.1. Request of the interested party. 3.2.2. Likelihood of the right. 3.2.3. Damage danger. 3.2.4. Irreversibility of the effects of the decision. 3.3. Reasons of the decision. 3.4. Actions for the effectiveness of the measure. 4. The urgency satisfying tutelage required in previous character. 4.1. Requirements regarding the content of the request. 4.2. Continuation of the action when the emergency tutelage is not granted. 4.3 Continuation of the action when the emergency tutelage is granted. 4.3.1. The interposition (or not) of appeal. 4.3.2. Hypothesis of no addition of the initial application by the author and, at the same time, interposition appeal by the accused. 4.3.3. The stabilization of the early tutelage. 5. Final considerations. 
Revista Eletrônica de Direito Processual - REDP. Volume 16. Julho a dezembro de 2015

Periódico Semestral da Pós-Graduação Stricto Sensu em Direito Processual da UERJ

Patrono: José Carlos Barbosa Moreira. ISSN 1982-7636. pp. 391-415 http://www.e-publicacoes.uerj.br/index.php/redp/index

\section{CONSIDERAÇÕES INICIAIS}

A exposição de motivos do "Anteprojeto do Novo Código de Processo Civill", apresentada por comissão de juristas presidida pelo Ministro Luiz Fux ao Senado Federal em junho de 2010, logo nos seus primeiros parágrafos, aponta para aquilo que se pode considerar como um dos principais objetivos do novo diploma processual: tornar o processo civil um instrumento capaz de efetivamente entregar aos jurisdicionados a realização do Direito material pretendida ${ }^{2}$.

A intenção de que o sistema processual seja um meio efetivo para a realização do direito material não é uma novidade do novo Código. Nos últimos vinte anos, inúmeras e substanciais foram as aterações legislativas visando a evitar que a intempestividade ${ }^{3}$ na atividade jurisdicional decorrente do modelo de processo previsto originariamente pelo Código de Processo Civil de 1973, caracterizado pela rigidez de sua sistemática e pela heterogeneidade de seus procedimentos, viesse a prejudicar a tempestiva e efetiva realização do bem da vida pretendido.

O Código de Processo Civil de 1973, na sua versão original concebida por Alfredo Buzaid, mantinha uma divisão estanque entre os processos de conhecimento, de execução e cautelar, baseada em conceitos puramente processuais, impermeáveis ao direito material. ${ }^{4}$

2 Exposição de motivos do Anteprojeto do Novo Código de Processo Civil. Disponível em: http://www.senado.gov.br/senado/novocpc/pdf/anteprojeto.pdf. Acesso em: 30 de agosto de 2015. Está transcrito : Um sistema processual civil que não proporcione à sociedade o reconhecimento e a realização dos direitos, ameaçados ou violados, que têm cada um dos jurisdicionados, não se harmoniza com as garantias constitucionais de um Estado Democrático de Direito. Sendo ineficiente o sistema processual, todo o ordenamento jurídico passa a carecer de real efetividade. De fato, as normas de direito material se transformam em pura ilusão, sem a garantia de sua correlata realização, no mundo empírico, por meio do processo.

${ }^{3}$ Sobre intempestividade processual, leia-se: JOBIM, Marco Félix. O direito à duração razoável do processo: responsabilidade civil do Estado em decorrência da intempestividade processual. 2. ed. rev. e ampl. Porto Alegre: São Paulo, 2012.

${ }^{4}$ Como bem esclarece Daniel Mitidiero, “o Antreprojeto de Código de Processo Civil entregue por Alfredo Buzaid em 1964 para o Governo Federl contém apenas a redação dos três primeiros livros do Código, correspondentes ao processo de conhecimento (arts. $1^{\circ}$ a 612), ao processo de execução (arts. 613 a 845) e ao processo cautelar (arts. 846 a 913). Não contempla a redação do livro quarto, correspondente aos procedimentos especiais de jurisdição contenciosa e de jurisdição voluntária... Na sua ótica, muitíssimo provavelmente bastavam apenas o processo de conhecimento, o processo de execução e o processo cautelar para organização de um Código de Processo Civil. Intimamente, Alfredo Buzaid possivelmente considerava finda a sua missão com a redação dos três primeiros livros do Anteprojeto. O que interessava para o Direito processual civil eram 
Revista Eletrônica de Direito Processual - REDP. Volume 16. Julho a dezembro de 2015

Periódico Semestral da Pós-Graduação Stricto Sensu em Direito Processual da UERJ

Patrono: José Carlos Barbosa Moreira. ISSN 1982-7636. pp. 391-415 http://www.e-publicacoes.uerj.br/index.php/redp/index

Pretendia que qualquer causa pudesse ser tratada, independentemente da natureza do Direito material posto em juízo, mediante um procedimento padrão. ${ }^{5}$

Em decorrência de tal formatação, a realização do Direito material, quando não fundada em título executivo extrajudicial, dependia, sempre, de decisão de mérito construída mediante um processo de cognição exauriente, com profundo debate acerca do seu objeto. Certamente, de nenhum modo instantâneo, pois, conforme aponta Teori Zavascki, "entre o pedido e a entrega efetiva - período durante o qual se exercerão o contraditório e a ampla defesa - decorrerá, necessariamente, um razoável espaço de tempo, por mais sumário que seja o rito procedimental e por mais eficientes que sejam os serviços judiciários". 6

Com o passar dos anos, o meio jurídico, felizmente, voltou os olhos para algumas situações fáticas incompatíveis com aquele modelo de processo padrão, por exigirem prestação jurisdicional urgente. Situações em que, ou a realização do Direito material é promovida imediatamente, ou o processo não dará à parte aquilo, tudo aquilo e exatamente aquilo a que ela tem direito, não cumprindo o Estado, pois, com o compromisso de entregar tutela adequada e efetiva. Afinal, é direito de quem litiga em juízo obter do Estado a entrega da tutela em tempo e em condições adequadas a preservar, de modo efetivo, o bem da vida que lhe for devido, ${ }^{7}$ nada importando um direito, como refere Daniel Mitidiero, "se não existem técnicas processuais idôneas para sua efetiva realização". 8

Nesse contexto, sobreveio a Lei no 8.952/1994 que, ao dar nova redação ao art. 273 do Código de Processo Civil de 1973, consagrou a possibilidade de o juiz, atendidos certos requisitos, antecipar, em qualquer processo de conhecimento, os efeitos da tutela definitiva de mérito. Também, na mesma reforma processual, foi alterada a redação do art. 461, de modo a prever que, nas ações que tenham por objeto obrigação de fazer ou não fazer, poderá a tutela específica ser concedida liminarmente pelo juiz. Com a Lei $n^{\circ} 10.444 / 2002$, foi

\footnotetext{
apenas conceitos puramente processuais, impermeáveis ao Direito material”. (MITIDIERO, Daniel. O processualismo e a formação do Código Buzaid. In: JOBIM, Geraldo Cordeiro; JOBIM, Marco Félix; TELLINI, Denise Estrela (org.). Tempestividade e Efetividade Processual: Novos Rumos do Processo Civil Brasileiro. Caxias do Sul: Editora Plenum, 2010, p. 117).

${ }^{5}$ Idem, p. 118-120.

${ }^{6}$ ZAVASCKI, Teori Albino. Antecipação da tutela. 4. ed. rev. e ampl. São Paulo: Saraiva, 2005, p. 25.

${ }^{7}$ Idem, p. 27.

${ }^{8}$ MITIDIERO, Daniel. Antecipação da tutela: da tutela cautelar à técnica antecipatória. Sâo Paulo: Revista dos Tribunais, 2013, p. 16.
} 
Revista Eletrônica de Direito Processual - REDP. Volume 16. Julho a dezembro de 2015

Periódico Semestral da Pós-Graduação Stricto Sensu em Direito Processual da UERJ

Patrono: José Carlos Barbosa Moreira. ISSN 1982-7636. pp. 391-415 http://www.e-publicacoes.uerj.br/index.php/redp/index

introduzido o art. 461-A, o qual permitiu a concessão liminar da tutela específica também para as ações que tenham por objeto a entrega de coisa; ainda, foi estendida às hipóteses do art. 273 a utilização dos meios de coerção para a realização da ordem judicial, previstos nos $\S \S 4^{\circ}$ e $5^{\circ}$ do art. 461.

A consagração da antecipação da tutela foi, sem dúvida, um grande avanço para dar efetividade ao processo ${ }^{9}$. Agora, com a entrada em vigor do Código de Processo Civil de 2015, outras novidades surgem na busca de um modelo processual capaz de proporcionar aos jurisdicionados a efetiva realização do Direito material, alterando substancialmente o procedimento relativo à antecipação da tutela fundada na urgência.

O que o presente estudo se propõe, pois, é justamente analisar como é regulada a tutela satisfativa de urgência no Código de Processo Civil de 2015. Para tanto, buscar-se-á, em um primeiro momento, diferenciar a tutela de urgência da tutela da evidência e, dentre as tutelas de urgência, diferenciar a tutela satisfativa da tutela cautelar. Após, serão verificadas as características da tutela de urgência satisfativa e os requisitos necessários para a sua concessão. Por fim, a atenção se voltará para o procedimento da tutela de urgência satisfativa requerida em caráter antecedente, uma grande novidade no sistema processual brasileiro.

\section{TUTELA PROVISÓRIA}

O Código de Processo Civil de 2015 foi construído de modo a prever um procedimento apto à prestação de uma tutela jurisdicional adequada, efetiva e tempestiva. Este procedimento, conforme destacado por Luiz Guilherme Marinoni, Sérgio Cruz Arenhart e Daniel Mitidiero, "pode levar à prestação de uma tutela definitiva fundada em cognição exauriente ou a uma tutela provisória fundada em cognição sumária” ${ }^{10} \mathrm{O}$ Código de Processo Civil de 2015 trata, no Livro V de sua Parte Geral, daquilo que denomina de

\footnotetext{
${ }_{9}^{9}$ MARINONI, Luiz Guilherme. Antecipação da tutela. 11. ed. rev. e atual. São Paulo: Revista dos Tribunais, 2010 , p. 29.

${ }^{10}$ MARINONI, Luiz Guilherme; ARENHART, Sérgio Cruz; MITIDIERO, Daniel. Novo Curso de Processo Civil: tutela dos direitos mediante procedimento comum, volume II. São Paulo: Revista dos Tribunais, 2015, p. 47.
} 
Revista Eletrônica de Direito Processual - REDP. Volume 16. Julho a dezembro de 2015

Periódico Semestral da Pós-Graduação Stricto Sensu em Direito Processual da UERJ

Patrono: José Carlos Barbosa Moreira. ISSN 1982-7636. pp. 391-415 http://www.e-publicacoes.uerj.br/index.php/redp/index

Tutela Provisória, a qual, de acordo com o caput do art. 294, pode se fundamentar em duas hipóteses: na urgência e na evidência.

A tutela da evidência ${ }^{11}$ visa a distribuir o ônus do tempo no processo, independentemente de haver ou não urgência, de modo a privilegiar aquele que provavelmente possui razão. ${ }^{12}$ Consiste na antecipação da tutela de mérito quando da ocorrência de alguma das hipóteses taxativas previstas nos incisos do artigo 311 (I - quando ficar caracterizado o abuso de direito de defesa ou o manifesto propósito protelatório da parte; ${ }^{13} \mathrm{II}$ - quando a prova documental for suficiente para provar os fatos alegados e houver tese firmada em julgamento de casos repetitivos ou em súmula vinculante; III - quando se tratar de pedido reipersecutório fundado em prova documental adequada do contrato de depósito; IV - quando a petição inicial for instruída com prova documental suficiente dos direitos do autor, a que o réu não oponha prova capaz de gerar dúvida razoável)

A tutela fundamentada na urgência, por sua vez, será concedida, de acordo com o que prevê o caput do artigo 300, quando houver elementos que evidenciem a probabilidade do direito e o perigo de dano ou o risco ao resultado útil do processo, sendo subdividida em tutela antecipada e tutela cautelar, as quais se distinguem pela sua natureza.

Existe direito à satisfação dos direitos e existe direito à sua asseguração. ${ }^{14} \mathrm{~A}$ tutela cautelar ${ }^{15}$ é meio de preservação de outro Direito - o Direito objeto da tutela satisfativa -, ${ }^{16}$ tendo como propósito conservar a tutela do Direito material para sua eventual e futura satisfação. ${ }^{17}$ A tutela antecipada, diferentemente, antecipa a realização da própria tutela satisfativa do direito. De acordo com Guilherme Rizzo Amaral, a tutela antecipada "tem

\footnotetext{
${ }^{11}$ A tutela da evidência não é objeto do presente estudo, de modo que será apenas superficialmente definida com a única intenção de distingui-la das tutelas fundadas na urgência.

12 AMARAL, Guilherme Rizzo. Comentários às alterações do novo CPC. São Paulo: Revista dos Tribunais, 2015, p. 415.

${ }^{13}$ A hipótese do inc. I do art. 311 era a única que, ainda durante a vigência do Código de 1973, permitia a antecipação da tutela (art. 273, inc. II).

${ }^{14}$ MARINONI, Luiz Guilherme; ARENHART, Sérgio Cruz; MITIDIERO, Daniel. Novo Curso de Processo Civil... Op. Cit., p. 197.

${ }^{15}$ Assim como a tutela da evidência, a tutela cautelar também não será aqui analisada, mas tão somente referida e brevemente definida com o fim de distingui-la da tutela antecipada de mérito fundada na urgência.

${ }^{16}$ DIDIER JR., Fredie; BRAGA, Paula Sarno; OLIVEIRA, Rafael Alexandria de. Curso de processo civil: teoria da prova, direito probatório, ações probatórias, decisão, precedente, coisa julgada e antecipação dos efeitos da tutela. Salvador: Jus Podivm, 2015, p. 562.

${ }^{17}$ MARINONI, Luiz Guilherme; ARENHART, Sérgio Cruz; MITIDIERO, Daniel. Novo Código de Processo Civil Comentado. São Paulo: Revista dos Tribunais, 2015, p. 309.
} 
Revista Eletrônica de Direito Processual - REDP. Volume 16. Julho a dezembro de 2015

Periódico Semestral da Pós-Graduação Stricto Sensu em Direito Processual da UERJ

Patrono: José Carlos Barbosa Moreira. ISSN 1982-7636. pp. 391-415 http://www.e-publicacoes.uerj.br/index.php/redp/index

ínsita a característica de satisfazer o direito, dado que somente com a satisfação, ainda que provisória, assegura-se a concretização futura da tutela definitiva do direito". ${ }^{18}$ É sobre esta última, a antecipação - fundada na urgência - da tutela satisfativa do direito que se debruça o presente estudo.

\section{TUTELA DE URGÊNCIA SATISFATIVA}

\subsection{Momento do requerimento}

A tutela de urgência satisfativa, de acordo com o que dispõe o parágrafo único do artigo 294 do Código de 2015, pode ser requerida em caráter antecedente ou incidental.

Considera-se incidental quando requerida dentro do processo em que se pede ou já se pediu a tutela definitiva, quer dizer, na própria petição inicial conjuntamente ao pedido de tutela definitiva ou, ainda, no curso do processo. Trata-se da mesma espécie de técnica antecipatória prevista no artigo 273 do Código de 1973, podendo ser deferida liminarmente ou após a oitiva da parte contrária.

A tutela requerida em caráter antecedente, por seu turno, trata-se de uma novidade do sistema processual brasileiro, trazida pelo Código de 2015. É aquela que precede ao processo em que se pretende, no futuro, pedir a tutela definitiva. ${ }^{19} \mathrm{O}$ procedimento da tutela satisfativa de urgência requerida em caráter antecedente será, adiante, mais detidamente analisada.

Independentemente de o requerimento da tutela de urgência ser realizado em caráter antecedente ou incidental, não haverá acréscimo de custas processuais em relação àquelas decorrentes do pedido da tutela jurisdicional final. Quando a tutela de urgência for requerida em caráter antecedente, não haverá novas custas no momento da realização do pedido de tutela definitiva, conforme preceitua o parágrafo $3^{\circ}$ do artigo 303 do Código de 2015. Quando a tutela for requerida em caráter incidental, o pagamento das custas estará somente

\footnotetext{
${ }^{18}$ AMARAL, Guilherme Rizzo, Op. Cit., p. 394.

${ }^{19}$ DIDIER JR., Fredie; BRAGA, Paula Sarno; OLIVEIRA, Rafael Alexandria de. Op. Cit., p. 570.
} 
Revista Eletrônica de Direito Processual - REDP. Volume 16. Julho a dezembro de 2015

Periódico Semestral da Pós-Graduação Stricto Sensu em Direito Processual da UERJ

Patrono: José Carlos Barbosa Moreira. ISSN 1982-7636. pp. 391-415 http://www.e-publicacoes.uerj.br/index.php/redp/index

vinculado ao pedido principal, de acordo com o que dispõe o artigo 295 do novo diploma processual.

\subsection{Requisitos necessários para a sua concessão}

\subsubsection{Requerimento da parte interessada}

Nas disposições do Código de 2015 acerca da antecipação da tutela (e das tutelas provisórias em geral), não há expressa menção acerca da necessidade do requerimento do interessado para a concessão da tutela de forma antecipada. Contudo, tal exigência fica clara mediante a leitura dos artigos $2^{\circ}, 141$ e 492, sendo certa, pois, a necessidade de requerimento da parte, em atenção ao princípio da demanda. ${ }^{20}$

Nem poderia ser diferente. Considerando que o artigo 302 determina que a parte é objetivamente responsável pelo prejuízo que a efetivação da tutela de urgência causar à parte adversa em caso de reforma ou cassação da decisão, mostra-se imprescindível que a parte requeira a concessão da tutela antecipada, de modo a, conscientemente, assumir o risco de ter de reparar a outra parte, se restar vencida no processo. ${ }^{21}$ Não é permitido ao juiz, pois, a antecipação da tutela de ofício.

Diferente situação é aquela em que o juiz consulta a parte acerca de seu interesse na obtenção da tutela antecipada, o que pode ocorrer, tendo em conta a estrutura cooperativa do novo processo civil. ${ }^{22}$

\subsubsection{Probabilidade do direito}

O caput do artigo 300 do Código de 2015 determina que seja demonstrada, para a concessão da medida, a probabilidade do direito cuja tutela se pretende antecipar. Ao

\footnotetext{
${ }^{20}$ MARINONI, Luiz Guilherme; ARENHART, Sérgio Cruz; MITIDIERO, Daniel. Novo Curso de Processo Civil.... Op. Cit., p. 205.

${ }^{21}$ DIDIER JR., Fredie; BRAGA, Paula Sarno; OLIVEIRA, Rafael Alexandria de. Op. Cit., p. 594.

${ }^{22}$ MARINONI, Luiz Guilherme; ARENHART, Sérgio Cruz; MITIDIERO, Daniel. Novo Código de Processo Civil..., Op. Cit., p. 307.
} 
Revista Eletrônica de Direito Processual - REDP. Volume 16. Julho a dezembro de 2015

Periódico Semestral da Pós-Graduação Stricto Sensu em Direito Processual da UERJ

Patrono: José Carlos Barbosa Moreira. ISSN 1982-7636. pp. 391-415 http://www.e-publicacoes.uerj.br/index.php/redp/index

verificar o preenchimento desse requisito, deve o magistrado avaliar se há elementos que evidenciem ser provável ter acontecido o que foi narrado pela parte, de acordo com os elementos apresentados nos autos, e quais as chances de êxito decorrentes da narrativa. ${ }^{23}$

A probabilidade do direito que autoriza o emprego da técnica antecipatória para a tutela dos direitos, como referem Luiz Guilherme Marinoni, Sérgio Cruz Arenhart e Daniel Mitidiero, "é a probabilidade lógica - que é aquela que surge da confrontação das alegações e das provas com os elementos disponíveis nos autos, sendo provável a hipótese que encontra maior grau de confirmação e menor grau de refutação nesses elementos". ${ }^{24}$

Diferentemente do Código de 1973, quando era exigido para a concessão da antecipação da tutela que a verossimilhança da alegação estivesse fundada em prova inequívoca, na sistemática do Código de 2015, o juízo de probabilidade não está atrelado, necessariamente, à existência de prova. Trata-se, nas palavras de Guilherme Rizzo Amaral, de opção "por uma maior abertura de um dos requisitos para a concessão da tutela de urgência". 25

Assim, se o magistrado, ao analisar os elementos constantes nos autos, concluir ser provável que a parte que requereu a antecipação de tutela possua razão, preenchido estará o requisito para a sua concessão. Se se convencer do contrário, a medida não deverá ser deferida.

\subsubsection{Perigo de dano}

O caput do artigo 300 apresenta, também, exigência relacionada à necessidade da concessão da medida. Trata-se, precisamente, da existência do elemento que justifica a antecipação da tutela: a urgência, a qual, de acordo com o texto legal, decorre do perigo de dano (que se relaciona com a tutela satisfativa) ou de risco ao resultado útil do processo (que se relaciona com a tutela cautelar). A demora no oferecimento da prestação jurisdicional

\footnotetext{
${ }^{23}$ DIDIER JR., Fredie; BRAGA, Paula Sarno; OLIVEIRA, Rafael Alexandria de. Op. Cit., p. 595.

${ }^{24}$ MARINONI, Luiz Guilherme; ARENHART, Sérgio Cruz; MITIDIERO, Daniel. Novo Curso de Processo Civil.... Op. Cit., p. 203.

${ }^{25}$ AMARAL, Guilherme Rizzo, Op. Cit., p. 400.
} 
Revista Eletrônica de Direito Processual - REDP. Volume 16. Julho a dezembro de 2015

Periódico Semestral da Pós-Graduação Stricto Sensu em Direito Processual da UERJ

Patrono: José Carlos Barbosa Moreira. ISSN 1982-7636. pp. 391-415 http://www.e-publicacoes.uerj.br/index.php/redp/index

deve representar, no caso concreto, risco para a efetividade da jurisdição e a eficaz realização do direito. ${ }^{26}$ Não restando evidenciado tal elemento, não há razão para que a tutela de mérito seja antecipada.

Parte da doutrina refere que não só nas hipóteses expressamente previstas em lei perigo de dano ou risco ao resultado útil do processo - a antecipação da tutela dever ser concedida, mas também quando houver risco de ilícito. Nesse sentido, Luiz Guilherme Marinoni, Sérgio Cruz Arenhart e Daniel Mitidiero referem que "a pretexto de retratar os casos de urgência, o legislador fala em 'perigo de dano' e em 'risco ao resultado útil do processo' (art. 300), como se inexistissem tutelas contra o perigo de ilícito (como, no entanto, assegura expressamente o art. 497, parágrafo único, que refere que 'para concessão da tutela específica destinada a inibir a prática, a reiteração ou a continuação de um ilícito, ou a sua remoção, é irrelevante a demonstração da ocorrência de dano ou da existência de culpa ou dolo')". ${ }^{27}$ Concluem, afirmando que "a tutela antecipada serve não só para combater um 'perigo de dano', mas também 'um perigo de ilícito"'. ${ }^{28}$ Guilherme Rizzo Amaral, alinhado a este entendimento, aduz que "não só o risco de dano, como também o risco de ilícito, autoriza a tutela de urgência". ${ }^{29}$

Sobre o ponto, ainda que se concorde que o perigo de ilícito em razão da demora autorize a concessão da medida antecipatória, poucas são as hipóteses que se consegue vislumbrar de um perigo de ilícito que não traga consigo, por mais inexpressivo ou longínquo que seja, um perigo de dano. Até mesmo porque, o Código de 2015 apresenta exigência menos restritiva em comparação ao Código de 1973 no que se refere ao perigo de dano. De acordo com o inciso I do artigo 273 do Código revogado, para que fosse concedida a antecipação da tutela satisfativa, deveria ser demonstrado fundado receio de dano irreparável ou de difícil reparação. No Código de 2015, não há a exigência de que o perigo seja de dano irreparável ou de difícil reparação. Basta que haja perigo de qualquer espécie de dano, por menos e mais remoto que ele seja.

\footnotetext{
${ }^{26}$ DIDIER JR., Fredie; BRAGA, Paula Sarno; OLIVEIRA, Rafael Alexandria de. Op. Cit., p. 597.

${ }^{27}$ MARINONI, Luiz Guilherme; ARENHART, Sérgio Cruz; MITIDIERO, Daniel. Novo Curso de Processo Civil.... Op. Cit., p. 197-198.

${ }^{28}$ Idem, p. 199.

${ }^{29}$ AMARAL, Guilherme Rizzo, Op. Cit., p. 400.
} 
Revista Eletrônica de Direito Processual - REDP. Volume 16. Julho a dezembro de 2015

Periódico Semestral da Pós-Graduação Stricto Sensu em Direito Processual da UERJ

Patrono: José Carlos Barbosa Moreira. ISSN 1982-7636. pp. 391-415 http://www.e-publicacoes.uerj.br/index.php/redp/index

Há quem defenda na doutrina que, embora não haja determinação expressa, o perigo de dano, para a concessão de medida antecipatória, deve ser irreparável ou de difícil reparação mesmo na vigência do Código de $2015 .{ }^{30}$ Contudo, não é de se supor que o legislador tenha simplesmente "esquecido" de repetir a exigência prevista no Código anterior, no sentido de que o risco deve ser de um dano irreparável ou de difícil reparação. Se deixou de fora tal exigência, certamente foi por uma opção no sentido de ampliar as hipóteses de concessão da medida antecipatória.

\subsubsection{Irreversibilidade dos efeitos da decisão}

O parágrafo $3^{\circ}$ do artigo 300 do Código de 2015, no mesmo sentido do que previa o parágrafo $2^{\circ}$ do artigo 273 do Código de 1973, determina que não será concedida a tutela de urgência de natureza antecipada quando houver perigo de irreversibilidade dos efeitos da decisão. Quer dizer, necessariamente deve ser possível retornar-se ao status quo ante caso se constate, no curso do processo, que deve a tutela ser alterada ou revogada. ${ }^{31}$ Trata-se de regra amplamente - e corretamente - criticada pela doutrina.

Luiz Guilherme Marinoni, Sérgio Cruz Arenhart e Daniel Mitidiero, por exemplo, defendem que a regra vai à contramão da lógica do provável que preside a tutela provisória, na medida em que, "tendo a técnica antecipatória o objetivo de combater o perigo na demora capaz de produzir um ato ilícito ou um fato danoso - talvez irreparável - ao direito provável, não há como não admitir a concessão dessa tutela sob o simples argumento de que ela pode trazer um prejuízo irreversível ao réu. Seria como dizer que o direito provável deve sempre ser sacrificado diante da possibilidade de prejuízo irreversível ao direito improvável - o que é obviamente um contrassenso". 32

O entendimento de Fredie Didier Jr., Paulo Sarno Braga e Rafael Alexandria de Oliveira é um pouco mais brando, no sentido de que a regra deve ser vista com

\footnotetext{
${ }^{30}$ Nesse sentido, DIDIER JR., Fredie; BRAGA, Paula Sarno; OLIVEIRA, Rafael Alexandria de. Op. Cit., p. 597; AMARAL, Guilherme Rizzo, Op. Cit., p. 400.

${ }^{31}$ DIDIER JR., Fredie; BRAGA, Paula Sarno; OLIVEIRA, Rafael Alexandria de. Op. Cit., p. 600.

${ }^{32}$ MARINONI, Luiz Guilherme; ARENHART, Sérgio Cruz; MITIDIERO, Daniel. Novo Código de Processo Civil..., Op. Cit., p. 313.
} 
Revista Eletrônica de Direito Processual - REDP. Volume 16. Julho a dezembro de 2015

Periódico Semestral da Pós-Graduação Stricto Sensu em Direito Processual da UERJ

Patrono: José Carlos Barbosa Moreira. ISSN 1982-7636. pp. 391-415 http://www.e-publicacoes.uerj.br/index.php/redp/index

temperamentos, apontando que também existe o perigo da irreversibilidade decorrente da não-concessão da medida, razão pela qual, havendo direitos em choque, deve-se invocar a proporcionalidade, cabendo ao "juiz ponderar os valores em jogo, dando proteção àquele que, no caso concreto, tenha maior relevo". ${ }^{33}$

Ambos os apontamentos são verdadeiros e devem ser sempre observados pelo magistrado quando da sua decisão pelo deferimento ou indeferimento da antecipação da tutela, de modo a que prevaleça a lógica da tutela do direito mais provável em detrimento do menos provável. Também é necessário que o julgador, quando em dúvida sobre qual o direito mais provável e sendo irreversíveis os efeitos da decisão em caso de concessão ou nãoconcessão da medida, utilize-se da proporcionalidade para verificar o que será menos danoso.

\subsection{Motivação da decisão}

Na decisão que conceder, negar, modificar ou revogar a tutela provisória, deve o magistrado fundamentar sua decisão de modo claro e preciso. É o que determina o artigo 298 do Código de 2015.

Luiz Guilherme Marinoni, Sérgio Cruz Arenhart e Daniel Mitidiero entendem que fundamentar de modo claro e preciso é "dar as razões que justificam a decisão", as quais devem enfrentar os fundamentos arguidos pela parte, apontando de forma clara no que precisamente essas razões servem para a solução do caso concreto. ${ }^{34}$

De acordo com o parágrafo $1^{\circ}$ do artigo 489, não se considera fundamentada a decisão judicial, seja ela qual for (interlocutória, sentença ou acórdão) que: I - se limitar à indicação, reprodução ou paráfrase de ato normativo, sem explicar sua relação com a causa ou a questão decidida; II - empregar conceitos jurídicos indeterminados; III - invocar motivos que se prestariam a justificar qualquer decisão; IV - não enfrentar todos os argumentos deduzidos no processo capazes de, em tese, infirmar a conclusão adotada pelo

\footnotetext{
${ }^{33}$ DIDIER JR., Fredie; BRAGA, Paula Sarno; OLIVEIRA, Rafael Alexandria de. Op. Cit., p. 600-601.

${ }^{34}$ MARINONI, Luiz Guilherme; ARENHART, Sérgio Cruz; MITIDIERO, Daniel. Novo Curso de Processo Civil.... Op. Cit., p. 210.
} 
Revista Eletrônica de Direito Processual - REDP. Volume 16. Julho a dezembro de 2015

Periódico Semestral da Pós-Graduação Stricto Sensu em Direito Processual da UERJ

Patrono: José Carlos Barbosa Moreira. ISSN 1982-7636. pp. 391-415 http://www.e-publicacoes.uerj.br/index.php/redp/index

julgador; V - se limitar a invocar precedente ou enunciado de súmula, sem identificar seus fundamentos determinantes nem demonstrar que o caso sob julgamento se ajusta àqueles fundamentos; VI - deixar de seguir enunciado de súmula, jurisprudência ou precedente invocado pela parte, sem demonstrar a existência de distinção no caso em julgamento ou a superação do entendimento.

Sendo assim, qualquer decisão que venha a recair sobre a antecipação da tutela satisfativa, seja para deferir ou para indeferir a medida, deve atender a tais exigências.

\subsection{Medidas para a efetivação da medida}

Uma vez concedida a tutela de urgência satisfativa, o Código de 2015, no artigo 297, atribui poder ao juiz para determinar as medidas que considerar adequadas para a sua efetivação.

Trata-se de regra que deve ser lida de forma vinculada ao que dispõe o inciso IV do artigo 139, o qual permite que o juiz atribua todas as medidas indutivas, coercitivas, mandamentais ou sub-rogatórias necessárias para assegurar o cumprimento de ordem judicial, inclusive nas ações que tenham por objeto prestação pecuniária. Quer dizer, não há uma forma específica para o juiz efetivar a tutela de urgência deferida, devendo optar pela mais adequada no caso concreto.

É fundamental que seja sempre observado pelo magistrado, quando da escolha da medida a ser utilizada, o critério da adequação expressamente referida no caput do artigo 297, ao qual, aliás, devem se somar os critérios da necessidade e da proporcionalidade em sentido estrito. Havendo mais de uma técnica possível de ser utilizada e igualmente eficaz, deve o magistrado, pois, optar por aquela que se mostrar menos gravosa para a parte adversa. ${ }^{35}$

\footnotetext{
${ }^{35}$ MARINONI, Luiz Guilherme; ARENHART, Sérgio Cruz; MITIDIERO, Daniel. Novo Código de Processo Civil..., Op. Cit., p. 310.
} 
Revista Eletrônica de Direito Processual - REDP. Volume 16. Julho a dezembro de 2015

Periódico Semestral da Pós-Graduação Stricto Sensu em Direito Processual da UERJ

Patrono: José Carlos Barbosa Moreira. ISSN 1982-7636. pp. 391-415 http://www.e-publicacoes.uerj.br/index.php/redp/index

\section{A TUTELA DE URGÊNCIA SATISFATIVA REQUERIDA EM CARÁTER ANTECEDENTE}

Para além da já conhecida antecipação de tutela requerida de forma simultânea ou posterior à propositura da ação, a nova sistemática do processo civil possibilita ao demandante requerer a tutela de urgência satisfativa antes mesmo da formulação do pedido da tutela definitiva.

$\mathrm{O}$ autor, primeiro, requer a concessão da tutela de urgência e, em momento posterior, postula a tutela definitiva. Trata-se da hipótese prevista no artigo 303 do Código de 2015. Para Luiz Guilherme Marinoni, Sérgio Cruz Arenhart e Daniel Mitidiero, tal inovação veio a "tornar procedimentalmente autônomo o juízo sumário que leva à concessão da tutela antecipada". ${ }^{36}$

A hipótese de a tutela de urgência ser requerida em caráter antecedente foi concebida para que não haja prejuízo de uma efetiva prestação jurisdicional naqueles casos em que, conforme referem Fredie Didier Jr., Paulo Sarno Braga e Rafael Alexandria de Oliveira, "a situação de urgência já é presente no momento da propositura da ação e, em razão disso, a parte não dispõe de tempo hábil para levantar os elementos necessários para formular o pedido de tutela definitiva (e respectiva causa de pedir) de modo completo e acabado, reservando-se a fazê-lo posteriormente." ${ }^{37}$

\subsection{Exigências relativas ao conteúdo do requerimento}

A tutela de urgência satisfativa requerida em caráter antecedente deve ser entendida, antes de tudo, como uma opção do autor, na medida em que traz consequências, quando concedida. Dentre elas, como se verá a seguir, está a possibilidade de a tutela vir a estabilizar-se, sem o prosseguimento do processo para o julgamento definitivo do mérito, o que, eventualmente, pode não ser de interesse do autor. Por isso, é fundamental que o autor

\footnotetext{
${ }^{36}$ MARINONI, Luiz Guilherme; ARENHART, Sérgio Cruz; MITIDIERO, Daniel. Novo Curso de Processo Civil.... Op. Cit., p. 214.

${ }^{37}$ DIDIER JR., Fredie; BRAGA, Paula Sarno; OLIVEIRA, Rafael Alexandria de. Op. Cit., p. 572.
} 
Revista Eletrônica de Direito Processual - REDP. Volume 16. Julho a dezembro de 2015

Periódico Semestral da Pós-Graduação Stricto Sensu em Direito Processual da UERJ

Patrono: José Carlos Barbosa Moreira. ISSN 1982-7636. pp. 391-415 http://www.e-publicacoes.uerj.br/index.php/redp/index

indique, expressamente, que pretende valer-se do benefício do requerimento de tutela antecipada em caráter antecedente, conforme determina o parágrafo $5^{\circ}$ do artigo 303.

Sem a expressa indicação do autor, não é possível estabilizar os efeitos da antecipação da tutela, devendo o magistrado analisar a petição inicial "como se esta se destinasse à instauração regular do processo visando à tutela plena e definitiva, e não com os requisitos mais limitados previstos no caput do art. 303 para a tutela antecipada em caráter antecedente". 38

Para além da indicação expressa do autor relativamente à sua intenção de valer-se do benefício do requerimento de tutela antecipada em caráter antecedente, o caput do artigo 303 exige que a petição inicial contenha: o requerimento da tutela antecipada; a indicação do pedido da tutela definitiva a ser posteriormente realizado; exposição sumária da causa de pedir, do direito que se busca realizar e do perigo de dano ou de ilícito. Ainda, em atenção à determinação contida no parágrafo $4^{\circ}$, deve o autor indicar o valor da causa considerando o pedido de tutela definitiva que presente formular.

\subsection{Prosseguimento da ação quando a tutela de urgência não for concedida}

Caso não venha a ser concedida a tutela, por não haver elementos que evidenciem o preenchimento dos seus pressupostos, deverá o magistrado determinar a intimação do autor para que promova a emenda da petição inicial no prazo de cinco dias, sob pena de indeferimento e extinção do processo sem resolução do mérito. É esta a regra contida no parágrafo $6^{\circ}$ do artigo 303 do Código de 2015.

Realizada a emenda da inicial pelo autor, com a complementação da causa de pedir, a confirmação do pedido de tutela definitiva e a juntada de documentos ainda ausentes, o processo prosseguirá o seu trâmite de acordo com as regras do procedimento comum, previstas no Código a partir do artigo 218.

\subsection{Prosseguimento da ação quando a tutela de urgência for concedida}

${ }^{38}$ AMARAL, Guilherme Rizzo, Op. Cit., p. 405. 
Revista Eletrônica de Direito Processual - REDP. Volume 16. Julho a dezembro de 2015

Periódico Semestral da Pós-Graduação Stricto Sensu em Direito Processual da UERJ

Patrono: José Carlos Barbosa Moreira. ISSN 1982-7636. pp. 391-415 http://www.e-publicacoes.uerj.br/index.php/redp/index

Caso a tutela satisfativa de urgência requerida em caráter antecedente venha a ser concedida, deve o juiz intimar o autor para que, no prazo de quinze dias ou em outro prazo maior devidamente fixado, providencie o aditamento da petição inicial, de modo a complementar a sua argumentação, juntar novos documentos e confirmar o pedido de tutela final, nos termos do inciso I do parágrafo $1^{\circ}$ do artigo 303.

De acordo com o parágrafo $2^{\circ}$ do artigo 303 , se, devidamente intimado, não venha o autor a aditar sua petição inicial nos termos e prazo previstos no inciso I do parágrafo $1^{\circ}, \mathrm{o}$ processo será extinto sem resolução do mérito. Havendo o aditamento da petição inicial, pelo autor, o processo prosseguirá, com a intimação e a citação do réu.

Deve o juiz, além disso, conforme preceitua o inciso II do parágrafo $1^{\circ}$ do artigo 303, determinar a citação e a intimação do réu para o cumprimento da tutela deferida, bem assim para que compareça à audiência de conciliação ou de mediação, na forma do art. 334, ou, sendo o caso, para que apresente a sua contestação.

Esta ordem cronológica de providências - primeiro a intimação do autor para o aditamento da inicial e, somente após, a citação e intimação do réu - não é expressamente estabelecida no Código de 2015. Contudo, trata-se de uma conclusão lógica, na medida em que não se pode exigir do réu que apresente sua contestação "sem o conhecimento pleno da extensão das postulações que contra si são feitas pelo autor", como bem observa Guilherme Rizzo Amaral. ${ }^{39}$

Há a possibilidade, no entanto, em decorrência da urgência e da natureza da medida concedida, que o réu, necessariamente, tenha que ser imediatamente intimado para cumprila. Nesse caso, em que pese não seja o Código de 2015 claro quanto ao ponto, parece que a interpretação mais correta é no sentido de que a citação e a intimação do réu tenham seus efeitos limitados, de modo tão somente a incluí-lo no polo passivo da ação e a exigir o cumprimento da medida, restando preservado, pois, o direito de o demandado apresentar sua contestação após o aditamento da petição inicial pelo autor. ${ }^{40}$

\footnotetext{
${ }^{39}$ Ibidem.

${ }^{40}$ Ibidem.
} 
Revista Eletrônica de Direito Processual - REDP. Volume 16. Julho a dezembro de 2015

Periódico Semestral da Pós-Graduação Stricto Sensu em Direito Processual da UERJ

Patrono: José Carlos Barbosa Moreira. ISSN 1982-7636. pp. 391-415 http://www.e-publicacoes.uerj.br/index.php/redp/index

4.3.1. A interposição (ou não) de recurso

Devidamente intimado, pode o réu interpor agravo de instrumento, que é o recurso cabível para impugnar decisão que concede tutela provisória, nos termos do artigo 1015, inciso I, do Código de 2015. Interposto o recurso, o procedimento comum se desenvolverá normalmente, rumo às suas etapas de saneamento, instrução e decisão. Se, contudo, o réu não recorrer, diz o caput do artigo 304, a tutela antecipada tornar-se-á estável e o processo será extinto, como preceitua o parágrafo $1^{\circ}$ do mesmo dispositivo legal.

A exigência de que o réu, para se contrapor ao deferimento da tutela antecipada, necessariamente interponha recurso, já é alvo de polêmica na doutrina. Guilherme Rizzo Amaral defende que a diç̧ão do caput do artigo 304 é clara, de modo que não há dúvida acerca da necessidade da interposição do recurso. ${ }^{41}$

De outro lado, posicionam-se Fredie Didier Jr., Paulo Sarno Braga e Rafael Alexandria de Oliveira, no sentido de que se, no "prazo de recurso, o réu não o interpõe, mas resolve antecipar o protocolo de sua defesa, fica afastada a sua inércia, o que impede a estabilização."42 Também é este o entendimento de Luiz Guilherme Marinoni, Sérgio Cruz Arenhart e Daniel Mitidiero, o qual merece a transcrição:

É claro que pode ocorrer de o réu não interpor o agravo de instrumento, mas desde logo oferecer contestação no mesmo prazo - ou, ainda, manifestar-se dentro desse mesmo prazo pela realização da audiência de conciliação ou de mediação. Nessa situação, tem-se que entender que a manifestação do réu no primeiro grau de jurisdição serve tanto quanto a interposição do recurso para evitar a estabilização dos efeitos da tutela. Essa solução tem a vantagem de economizar o recurso de agravo e de emprestar a devida relevância à manifestação de vontade constante da contestação ou do intento de comparecimento à audiência. Em ambas as manifestações, a vontade

\footnotetext{
${ }^{41}$ Idem, p. 407.

${ }^{42}$ DIDIER JR., Fredie; BRAGA, Paula Sarno; OLIVEIRA, Rafael Alexandria de. Op. Cit., p. 609.
} 
Revista Eletrônica de Direito Processual - REDP. Volume 16. Julho a dezembro de 2015

Periódico Semestral da Pós-Graduação Stricto Sensu em Direito Processual da UERJ

Patrono: José Carlos Barbosa Moreira. ISSN 1982-7636. pp. 391-415 http://www.e-publicacoes.uerj.br/index.php/redp/index

do réu é inequívoca no sentido de exaurir o debate com o prosseguimento do procedimento. ${ }^{43}$

Parece ser esta segunda, a menos restritiva, a melhor e mais lógica compreensão.

Importante esclarecer, ainda, que a extinção do processo referida no parágrafo $1^{\circ}$ do artigo 304 não se estende, logicamente, a eventuais pretensões do autor que não foram objeto de antecipação de tutela, em caso de cumulação de pedidos.

4.3.2. Hipótese de não aditamento da petição inicial pelo autor e, ao mesmo tempo, de não interposição de recurso pelo réu.

Admitindo-se a hipótese de deferimento de uma tutela de urgência em que o réu tenha que ser cientificado imediatamente para tomar a medida necessária para a efetivação da tutela, é a partir desse momento que se inicia o prazo para a interposição do recurso, em razão de sua ciência inequívoca. Nesse caso, como a situação se resolve se, porventura, o réu não recorra da decisão (o que conduz à extinção do processo com a estabilização da tutela antecipada) e, ao mesmo tempo, o autor, devidamente intimado, não adite a petição inicial (o que também conduz à extinção do processo)? Trata-se de hipótese claramente possível, mas não resolvida pelo legislador.

Considerando que, nessa situação, terá prestação de tutela jurisdicional, ainda que mediante juízo fundado em cognição sumária, devem os efeitos da decisão beseada na probabilidade do direito prevalecer, caso nenhuma das partes mostre interesse no prosseguimento do feito. Além disso, conforme destacado por Fredie Didier Jr., Paulo Sarno Braga e Rafael Alexandria de Oliveira, deve prevalecer a estabilização da tutela antecipada também "em razão da abertura conferida às partes de rever, invalidar ou reformar por meio da ação prevista no $\S 2^{\circ}$ do art. 304 do CPC." ${ }^{44}$

\footnotetext{
${ }^{43}$ MARINONI, Luiz Guilherme; ARENHART, Sérgio Cruz; MITIDIERO, Daniel. Novo Curso de Processo Civil.... Op. Cit., p. 216.

${ }^{44}$ DIDIER JR., Fredie; BRAGA, Paula Sarno; OLIVEIRA, Rafael Alexandria de. Op. Cit., p. 610.
} 
Revista Eletrônica de Direito Processual - REDP. Volume 16. Julho a dezembro de 2015

Periódico Semestral da Pós-Graduação Stricto Sensu em Direito Processual da UERJ

Patrono: José Carlos Barbosa Moreira. ISSN 1982-7636. pp. 391-415 http://www.e-publicacoes.uerj.br/index.php/redp/index

Parece ser esta a conclusão mais lógica, em que pese não haja dúvida que muita polêmica irá girar em torno da discussão.

\subsubsection{A estabilização da tutela antecipada}

A estabilização da tutela antecipada, disciplinada no artigo 304 do Código de 2015, trata-se de uma importante inovação no sistema processual brasileiro. Explicam Luiz Guilherme Marinoni, Sérgio Cruz Arenhart e Daniel Mitidiero que, não impugnada pelo réu a decisão que concede a tutela de urgência requerida em caráter antecedente, "a antecipação de tutela tem os seus efeitos estabilizados indefinidamente no tempo, a qual visa a empregar a técnica do contraditório eventual já presente no procedimento monitório com o fim de autonomizar e estabilizar a tutela antecipada fundada na urgência". ${ }^{45}$

Depois de estabilizada a tutela antecipada, somente pode ela ser revista, reformada ou invalidada mediante o ajuizamento de ação própria, que pode ser proposta por qualquer uma das partes, na qual se discutirá o mérito relacionado à tutela final. Não sendo ajuizada referida ação, ou enquanto não for ajuizada, a tutela antecipada estabilizada manterá seus efeitos. ${ }^{46}$

De acordo com o parágrafo $5^{\circ}$ do artigo 304, o direito de rever, reformar ou invalidar a tutela antecipada extingue-se após dois anos contados a partir da ciência das partes da decisão que extinguiu o processo. O parágrafo $6^{\circ}$, por sua vez, esclarece que a decisão que concede a tutela não fará coisa julgada, mas a estabilidade dos respectivos efeitos só será afastada por decisão proferida na ação autônoma proposta pelas partes, acima referida.

A natureza dessa imutabilidade e indiscutibilidade da decisão - que, como o próprio dispositivo legal refere, não se trata de coisa julgada -, é alvo de importante polêmica.

Para Luiz Guilherme Marinoni, Sérgio Cruz Arenhart e Daniel Mitidiero, é "de duvidosa legitimidade constitucional" a equiparação dos efeitos "do procedimento comum - realizado em contraditório, com ampla defesa e direito à prova - com os efeitos de um

\footnotetext{
${ }^{45}$ MARINONI, Luiz Guilherme; ARENHART, Sérgio Cruz; MITIDIERO, Daniel. Novo Código de Processo Civil..., Op. Cit., p. 316.

${ }^{46}$ AMARAL, Guilherme Rizzo, Op. Cit., p. 407.
} 
Revista Eletrônica de Direito Processual - REDP. Volume 16. Julho a dezembro de 2015

Periódico Semestral da Pós-Graduação Stricto Sensu em Direito Processual da UERJ

Patrono: José Carlos Barbosa Moreira. ISSN 1982-7636. pp. 391-415 http://www.e-publicacoes.uerj.br/index.php/redp/index

procedimento cuja sumariedade formal e material é extremamente acentuada". Esclarecem que, como a estabilização da tutela antecipada antecedente não pode lograr a autoridade da coisa julgada, passado o prazo de dois anos, “continua sendo possível o exaurimento da cognição até que os prazos previstos no direito material para a estabilização das situações jurídicas atuem sobre a esfera jurídica das partes". ${ }^{47}$

Guilherme Rizzo Amaral, de outro lado, refere tratar-se de prazo decadencial, dado que atinge o direito potestativo de ambas as partes, sendo que, uma vez "extinto o direito de propor tal ação, não parece haver saída se não reconhecer a imutabilidade dos efeitos da tutela antecipada, imunes a quaisquer outras ações que venham a ser movidas pelas partes". ${ }^{4}$

Trata-se de uma polêmica fadada a invencíveis controvérsias. Contudo, ainda que haja divergência acerca da natureza da decisão que estabiliza a tutela antecipada, não há como o prazo previsto no parágrafo $5^{\circ}$ ser desconsiderado. Portanto, levando-se em conta os termos dos parágrafos $5^{\circ}$ e $6^{\circ}$ do art. 304 , compreende-se que, passado o prazo de dois anos, a decisão torna-se imutável e indiscutível.

\section{CONSIDERAÇÕES FINAIS}

A busca pela aproximação do sistema processual ao Direito material é um traço marcante do Código de Processo Civil de 2015. Nesse contexto, o Livro V do Código, que trata da "Tutela Provisória", assume papel fundamental. É neste Livro que a tutela da evidência é acolhida - como instrumento apto a distribuir o ônus do tempo no processo - e que as medidas de urgência - satisfativa e cautelar - são disciplinadas.

Relativamente à tutela fundada na urgência de natureza satisfativa, o Código de Processo Civil de 2015 apresenta inúmeras e importantes inovações em comparação ao seu antecessor, notadamente no que diz respeito à possibilidade de ser requerida em caráter antecedente ao processo em que se pretende, no futuro, pedir a tutela definitiva.

\footnotetext{
${ }^{47}$ MARINONI, Luiz Guilherme; ARENHART, Sérgio Cruz; MITIDIERO, Daniel. Novo Curso de Processo Civil.... Op. Cit., p. 217-218.

48 AMARAL, Guilherme Rizzo, Op. Cit., 408.
} 
Revista Eletrônica de Direito Processual - REDP. Volume 16. Julho a dezembro de 2015

Periódico Semestral da Pós-Graduação Stricto Sensu em Direito Processual da UERJ

Patrono: José Carlos Barbosa Moreira. ISSN 1982-7636. pp. 391-415 http://www.e-publicacoes.uerj.br/index.php/redp/index

A tutela de urgência de natureza satisfativa requerida em caráter antecedente se apresenta como uma tentativa de evitar prejuízo a uma efetiva prestação jurisdicional naqueles casos em que a parte, em razão da situação de urgência, não dispõe de tempo hábil para fundamentar o pedido de tutela definitiva, podendo limitar a petição antecedente ao requerimento da tutela antecipada, à indicação do pedido da tutela definitiva a ser posteriormente realizado, a uma exposição sumária da causa de pedir, do direito que se busca realizar e do perigo de dano ou de ilícito e à indicação do valor da causa considerando o pedido de tutela definitiva que se presente formular.

A grande novidade acrescentada pelo novo Código se apresenta quando há a concessão da tutela de urgência de natureza satisfativa requerida em caráter antecedente. Nesse caso, se, porventura, o réu não recorrer da decisão (ou, como no entendimento de parte da doutrina, o réu não vier a impugnar a decisão de nenhum modo), haverá a estabilização da tutela provisória e a extinção do processo.

Por se tratar de uma novidade no sistema processual brasileiro, mas também em razão de um déficit de esclarecimento no texto do novo Código, a estabilização da tutela provisória, sem dúvida, será alvo de muitas polêmicas; algumas inclusive já identificáveis.

É o caso, por exemplo, da situação em que, concedida a tutela de urgência requerida em caráter antecedente, nem o réu recorra da decisão (o que conduz à extinção do processo com a estabilização da tutela antecipada) e nem o autor venha a aditar a petição inicial (o que também conduz à extinção do processo): nessa hipótese, devem os efeitos da decisão beseada na probabilidade do direito prevalecer? Entende-se que sim, mas o texto legal não é minimamente claro neste sentido ou em sentido contrário.

Relativamente aos requisitos necessários para a concessão da tutela de urgência, exige o Código de Processo Civil de 2015 que seja demonstrada a probabilidade do direito cuja tutela se pretende antecipar, cumulada com a demonstração da existência de perigo de dano (para a tutela de natureza satisfativa) ou de risco ao resultado útil do processo (para a tutela de natureza cautelar). Parte da doutrina entende que, ao lado das hipóteses de perigo de dano e de risco ao resultado útil ao processo, deve ser incluída a hipótese de perigo contra o ilícito. 
Revista Eletrônica de Direito Processual - REDP. Volume 16. Julho a dezembro de 2015

Periódico Semestral da Pós-Graduação Stricto Sensu em Direito Processual da UERJ

Patrono: José Carlos Barbosa Moreira. ISSN 1982-7636. pp. 391-415 http://www.e-publicacoes.uerj.br/index.php/redp/index

Como principal equívoco do Código de 2015 relativamente ao tema, pode-se apontar para a previsão do parágrafo $3^{\circ}$ do artigo 300 do Código de 2015, o qual determina que não será concedida a tutela de urgência de natureza antecipada quando houver perigo de irreversibilidade dos efeitos da decisão. Trata-se de dispositivo legal que, não só vai à contramão da lógica do provável que preside a tutela provisória, como também ignora a possibilidade da existência de perigo da irreversibilidade decorrente da não-concessão da medida.

De outro lado, o Código de 2015 acerta ao determinar que deve o magistrado, quando conceder, negar, modificar ou revogar a tutela provisória, fundamentar sua decisão de modo claro e preciso, levando em conta todas as disposições do artigo 489.

Entre erros e acertos, de uma maneira geral pode-se concluir que são benéficas as inovações trazidas pelo novo Código. No entanto, se tais inovações trarão efetivo benefício para os jurisdicionados, somente o tempo dirá. Não há dúvida, contudo, que muito debate haverá acerca da correta interpretação dos dispositivos previstos no novo Código relacionados à tutela satisfativa de urgência.

\section{REFERÊNCIAS BIBLIOGRÁFICAS}

ALEXY, Robert. Interpretação jurídica. In: ALEXY, Robert. Direito, razão, discurso: estudos para a filosofia do direito. Trad. Luís Afonso Heck. Porto Alegre: Livraria do Advogado, 2010.

- Teoria do discurso e direitos fundamentais. Trad. Maria Cláudia Cachapuz. In: HECK, Luís Afonso (org.). Direito natural, direito positivo, direito discursivo. Porto Alegre: Livraria do Advogado, 2010.

AMARAL, Guilherme Rizzo. As astreintes e o processo civil brasileiro: multa do artigo 461 do CPC e outras. Porto Alegre, Livraria do Advogado, 2004.

. Comentários às alterações do novo CPC. São Paulo: Revista dos Tribunais, 2015.

. Cumprimento e execução de sentença sob a ótica do formalismo-valorativo. Porto

Alegre: Livraria do Advogado, 2008. 
Revista Eletrônica de Direito Processual - REDP. Volume 16. Julho a dezembro de 2015

Periódico Semestral da Pós-Graduação Stricto Sensu em Direito Processual da UERJ

Patrono: José Carlos Barbosa Moreira. ISSN 1982-7636. pp. 391-415 http://www.e-publicacoes.uerj.br/index.php/redp/index

ARENHART, Sérgio Cruz. A tutela inibitória da vida privada. São Paulo: Revista dos Tribunais, 2000.

ÁVILA, Humberto. Teoria dos Princípios: da definição à aplicação dos princípios jurídicos. 15. ed. rev. atual. e ampl. São Paulo: Editora Malheiros, 2014.

BUENO, Cássio Scarpinella. Tutela Antecipada. São Paulo: Saraiva, 2004.

CALAMANDREI, Piero. Introdução ao Estudo Sistemático dos Procedimentos Cautelares.

Tradução da edição italiana de 1936 por Carla Roberta Andreasi Bassi. Campinas: Servanda, 2000 .

DIDIER JR., Fredie; BRAGA, Paula Sarno; OLIVEIRA, Rafael Alexandria de. Curso de processo civil: teoria da prova, direito probatório, ações probatórias, decisão, precedente, coisa julgada e antecipação dos efeitos da tutela. Salvador: Jus Podivm, 2015.

GRECO. Leonardo. A tutela da urgência e a tutela da evidência no Código de Processo Civil de 2015. In: RIBEIRO, Darci Guimarães; JOBIM, Marco Félix. Desvendando o novo CPC. Porto Alegre; Livraria do Advogado, 2015.

JOBIM, Marco Félix. O direito à duração razoável do processo: responsabilidade civil do Estado em decorrência da intempestividade processual. 2. ed. rev. e ampl. Porto Alegre: Livraria do Advogado, 2012.

LANES, Júlio Cesar Goulart. Fato e Direito no Processo Civil Cooperativo. São Paulo: Revista dos Tribunais, 2014.

; POZATTI, Fabrício Costa. O juiz como único destinatário da prova (?). In: DIDIER Jr., Fredie (coord. Geral); FERREIRA, William Santos; JOBIM, Marco Félix (coord.). Grandes Temas do Novo CPC, v. 5: Direito probatório. Fato e Direito no Processo Civil Cooperativo. Salvador: Juspodvm, 2015.

MACHADO, Fábio Cardoso. Comentários aos artigos 294 a 310. In: MELLO, Rafael Corte; GIORGI JR., Romulo Ponticelli. Novo Código de Processo Civil Anotado. Charleston, SC, EUA: Create Space Independent Publishing Platform, 2015.

MARINONI, Luiz Guilherme. Antecipação da tutela. 11. ed. rev. e atual. São Paulo: Revista dos Tribunais, 2010.

. Técnica processual e tutela dos direitos. São Paulo: Revista dos Tribunais, 2004. Tutela especifica: arts. 461, CPC e 84, CDC. São Paulo: Revista dos Tribunais, 2001. 
Revista Eletrônica de Direito Processual - REDP. Volume 16. Julho a dezembro de 2015

Periódico Semestral da Pós-Graduação Stricto Sensu em Direito Processual da UERJ

Patrono: José Carlos Barbosa Moreira. ISSN 1982-7636. pp. 391-415 http://www.e-publicacoes.uerj.br/index.php/redp/index

;; ARENHART, Sérgio Cruz; MITIDIERO, Daniel. Novo Código de Processo Civil

Comentado. São Paulo: Revista dos Tribunais, 2015.

. Novo Curso de Processo Civil: tutela dos direitos mediante procedimento comum, volume II. São Paulo: Revista dos Tribunais, 2015.

MITIDIERO, Daniel. Antecipação da tutela: da tutela cautelar à técnica antecipatória. Sâo

Paulo: Revista dos Tribunais, 2013.

. Colaboração no processo civil: pressupostos sociais, lógicos e éticos. 2. ed. rev. atual. e ampl. São Paulo; Ed. RT, 2011.

. O processualismo e a formação do Código Buzaid. In: JOBIM, Geraldo Cordeiro; JOBIM, Marco Félix; TELLINI, Denise Estrela (org.). Tempestividade e Efetividade Processual: Novos Rumos do Processo Civil Brasileiro. Caxias do Sul: Editora Plenum, 2010.

NERY JÚNIOR, Nelson; NERY, Rosa Maria de Andrade. Código de Processo Civil Comentado e Legislação Extravagante. $10^{\mathrm{a}}$ ed. rev. ampl. e atual. São Paulo: Revista dos Tribunais, 2007.

SILVA, Jaqueline Mielke da. A tutela provisória no novo Código de Processo Civil. Porto Alegre: Verbo Jurídico, 2015.

SILVA, Ovídio Araújo Baptista da. Curso de processo civil, vol. 2: processo cautelar (tutela de urgência). $4^{\mathrm{a}}$ ed. rev. atual. Rio de Janeiro: Forense, 2007.

. Do Processo Cautelar. Rio de Janeiro: Forense, 1999.

Processo e Ideologia - O paradigma racionalista. Rio de Janeiro: Forense, 2004.

TALAMINI, Eduardo. Tutela de urgência no Projeto de novo Código de Processo Civil: a estabilização da medida urgente e a 'monitorização' do processo brasileiro. Revista de Processo. São Paulo: Revista dos Tribunais, 2012, n. 209.

TESHEINER, José Maria Rosa. Antecipação de tutela e litisregulação. Disponível em: $<$ http://www.academia.edu/1318567/Antecipa\%C3\%A7\%C3\%A3o_de_tutela_e_litisregul a\%C3\%A7\%C3\%A3o_estudo_em_homenagem_a_Athos_Gusm\%C3\%A3o_Carneiro>. Acesso em: 30 jun. 2015.

. Processo Cautelar. São Paulo: Saraiva, 1974. 
Revista Eletrônica de Direito Processual - REDP. Volume 16. Julho a dezembro de 2015

Periódico Semestral da Pós-Graduação Stricto Sensu em Direito Processual da UERJ

Patrono: José Carlos Barbosa Moreira. ISSN 1982-7636. pp. 391-415 http://www.e-publicacoes.uerj.br/index.php/redp/index

ZAVASCKI, Teori Albino. Antecipação da tutela. 4. ed. rev. e ampl. São Paulo: Saraiva, 2005. 